\title{
Diagnostic Evaluation of Non-Interpretable Results Associated with rpoB Gene in Genotype MTBDRplus Ver 2.0
}

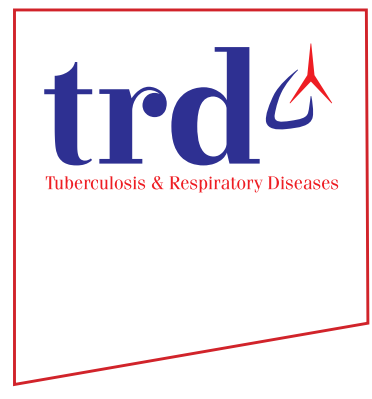

\author{
Binit Kumar Singh, Ph.D. ${ }^{1}{ }^{\mathbb{D}}$, Rohini Sharma, Ph.D. ${ }^{1}$, Parul Kodan, M.D. ${ }^{1}$, Manish Soneja, M.D. ${ }^{1}$ (iD), \\ Pankaj Jorwal, M.D. ${ }^{1}$, Neeraj Nischal, M.D. ${ }^{1}$, Ashutosh Biswas, M.D. ${ }^{1}$, Sanjay Sarin, M.D. ${ }^{2}$, Ranjani \\ Ramachandran, M.D. ${ }^{3}$ and Naveet Wig, M.D. ${ }^{1}$
}

${ }^{1}$ Department of Medicine, All India Institute of Medical Sciences, New Delhi, ${ }^{2}$ Foundation for Innovative New Diagnostics (FIND), New Delhi, ${ }^{3}$ World Health Organization, New Delhi, India

Background: Line probe assay (LPA) is standard diagnostic tool to detect multidrug resistant tuberculosis. Noninterpretable (NI) results in LPA (complete missing or light wild-type 3 and 8 bands with no mutation band in rpoB gene region) poses a diagnostic challenge.

Methods: Sputum samples obtained between October 2016 and July 2017 at the Intermediate Reference Laboratory, All India Institute of Medical Sciences Hospital, New Delhi, India were screened. Smear-positive and smear-negative culturepositive specimens were subjected to LPA Genotype MTBDRplus Ver 2.0. Smear-negative with culture-negative and culture contamination were excluded. LPA NI samples were subjected to phenotypic drug susceptibility testing (pDST) using MGIT-960 and sequencing.

Results: A total of 1,614 sputum specimens were screened and 1,340 were included for the study (smear-positive $[\mathrm{n}=1,188]$ and smear-negative culture-positive $[\mathrm{n}=152])$. LPA demonstrated $1,306(97.5 \%)$ valid results with TUB (Mycobacterium tuberculosis) band, $24(1.8 \%) \mathrm{NI}$, three $(0.2 \%)$ valid results without TUB band, and seven $(0.5 \%)$ invalid results. Among the NI results, 22 isolates $(91.7 \%)$ were found to be rifampicin (RIF) resistant and two (8.3\%) were RIF sensitive in the pDST. Sequencing revealed that $r p o B$ mutations were noted in all 22 cases with RIF resistance, whereas the remaining two cases had wild-type strains. Of the 22 cases with $r p o B$ mutations, the most frequent mutation was S531W ( $\mathrm{n}=10,45.5 \%)$, followed by S531F ( $\mathrm{n}=6,27.2 \%)$, L530P ( $\mathrm{n}=2,9.1 \%)$, A532V ( $\mathrm{n}=2,9.1 \%)$, and L533P ( $\mathrm{n}=2,9.1 \%)$.

Conclusion: The present study showed that the results of the Genotype MTBDRplus assay were NI in a small proportion of isolates. pDST and $r p o B$ sequencing were useful in elucidating the cause and clinical meaning of the NI results.

Keywords: Mycobacterium tuberculosis Complex; Line Probe Assay; Drug Susceptibility Testing; Sequencing

Address for correspondence: Manish Soneja, M.D.

Department of Medicine, All India Institute of Medical Sciences, New Delhi 110 029, India

Phone: 91-011-2659-4641, Fax: 91-011-2659-6690

E-mail: manishsoneja@gmail.com

Received: Apr. 16, 2020

Revised: Jul. 6, 2020

Accepted: Aug. 5, 2020

Published online: Aug. 5, 2020

(c) It is identical to the Creative Commons Attribution Non-Commercial License (http://creativecommons.org/licenses/by-nc/4.0/).

\section{Introduction}

The high morbidity and mortality associated with drug resistant tuberculosis (DR-TB) makes it a matter of grave concern ${ }^{1}$. The widespread availability of rapid molecular diagnostic techniques has improved the case detection rate for DR-TB ${ }^{2}$. World Health Organization (WHO) approved the first version of line probe assay (Genotype MTBDRplus Ver 1.0, Hain Lifescience, Nehren, Germany [LPA V.1]) in 2008. The utility was limited to higher grade of smear-positive and culture-positive samples ${ }^{3}$. An improved version of line probe assay (LPA) (Genotype MTBDRplus Ver 2.0, Hain Lifescience [LPA V.2]) was endorsed by WHO in $2011^{4}$ which has high 
sensitivity and specificity when compared to Xpert MTB/ $\mathrm{RIF}^{5,6}$.

DNA based molecular diagnostics are based on screening alterations in the nucleic acid sequences. The principle of LPA is based on $r p o B$ gene, an 81 base-pair rifampicin (RIF) resistance-determining region which accounts about 95\% of RIF resistance. Missing of wild-type (WT) bands with or without presence of mutation (MUT) bands is interpreted as resistant. RIF specific mutation, S531L, H26Y, H526D, and D516V are the most prevalent mutation found in $r p o B$ gene in $\mathrm{LPA}^{2,7}$. Disputed mutations have also been observed at positions L511P, D516Y, H526L, and L533P in rpoB gene ${ }^{8,9}$. In LPA $\mathrm{V} .2$, a strain having missing or light band of WT3 (codon 513 to 517) or WT8 (codon 530 to 533) without any MUT band, could be due to silent mutation ${ }^{7}$ and failure of hybridization probe $^{10}$. Non-interpretable (NI) results in LPA V.2., albeit a small proportion, are a diagnostic challenge. Our study evaluated the role of phenotypic drug susceptibility testing (pDST) and sequencing in NI results of LPA V.2.

\section{Materials and Methods}

\section{Subject recruitment}

Sputum samples were received at the Intermediate Reference Laboratory (IRL) between October 2016 to July 2017 from the directly observed treatment short-course centers and medical out-patient department of All India Institute of Medical Sciences Hospital (AIIMS), New Delhi, India were evaluated for inclusion in the study. Smear-positive and smear-negative culture-positive specimens were included in the study. Smear-negative with culture-negative and culture contamination were excluded.

Investigations were conducted at the IRL of the Department of Medicine at the AIIMS, New Delhi, India. The sputum specimens were processed in bio-safety cabinet II in a bio-safety level-3 laboratory. As per laboratory protocol, sputum samples of all tuberculosis (TB) suspects were subjected to smear microscopy by Ziehl-Neelsen (ZN) staining and Mycobacterial Growth Indicator Tube (MGIT)-960 liquid culture (LC). Before decontamination, sputum samples were subjected to direct smear microscopy examination by the $\mathrm{ZN}$ method. The samples were decontaminated using the NALC-NaOH method (final $\mathrm{NaOH}$ concentration, $1 \%$ ). The decontaminated samples were then subjected to LPA and inoculated in LC and indirect drug susceptibility testing was performed by using the final critical concentration of anti-TB drugs, i.e., 0.1 $\mu \mathrm{g} / \mathrm{mL}$ of isoniazid (INH) and $1.0 \mu \mathrm{g} / \mathrm{mL}$ of RIF. Immunochromatographic test was done on all culture-positive samples using immunochromatographic assay kit (SD MPT64TB Ag kit, Standard Diagnostics, Suwon, Korea).

LPA was done using LPA kit (Genotype MTBDRplus Ver
2.0, Hain Lifescience) and the results were interpreted based on the operating manual provided by the manufacturer, valid results with TUB (Mycobacterium tuberculosis) band: presence of conjugate control (CC) and amplification control (AC) bands with all loci bands of WT and/or MUT bands; valid results without TUB band: presence of only CC and AC bands (without WT and MUT bands); NI: presence of TUB band and all loci bands with completely missing or light band of WT3 or WT8 without any MUT band in rpoB gene; invalid: presence of TUB band without control probes ${ }^{7}$. LPA NI samples were subjected to pDST using MGIT-960 and sequencing.

Sanger based sequencing was used as a reference standard for this study. Sequencing was performed for $r p o B$ gene (forward primer 5'-CAGACGTTGATCAACATCCG-3' and reverse primer 5'-TACGGCGTTTCGATGAAC-3' ${ }^{11}$ on ABI prism 3130xl genetic analyzer (Applied Biosystems and Hitachi, Ltd., Carlsbad, CA, USA).

\section{Statistical analysis}

The nucleotide sequence chromatograms were analyzed using BioEdit Software (Thomas Hall, Raleigh, NC, USA) and ClustalW 2.0. Data was entered and analyzed in Microsoft Excel. No patient particulars were recorded.

\section{Ethical approval}

The study was conducted in samples collected under the national program with no patient interviews. Ethics approval was thus not required.

\section{Results}

Out of total 1,614 sputum specimens, 1,212 (75.1\%) were smear-positive and $402(24.9 \%)$ were found to be smear-negative using ZN staining and microscopy. Among smear-positive specimens, 1,166 of 1,212 (96.2\%) were culture-positive, 22 of 1,212 (1.8\%) were culture-negative and contamination was found in 24 of 1,212 (2\%) specimens. Among smear-negative specimens, 152 of 402 (37.8\%) were culture-positive, 228 of $402(56.7 \%)$ were culture-negative and rest 22 of 402 (5.5\%) were found to be contaminated in LC (Table 1). After satisfying the inclusion and exclusion criteria, 1,340 samples were included for the study. All smear-positive specimens were directly processed for the LPA while, in case of smear-negative specimens, LPA were done only when the culture turned positive in LC (indirect).

\section{Performance of line probe assay (LPA V.2)}

LPA detected 1,306 of 1,340 valid results with TUB band (97.5\%) and 24 of 1,340 NI results (1.8\%) (Table 1). Among 
Table 1. Diagnostic performance parameter of Genotype MTBDRplus Ver $2.0(n=1,340)$

\begin{tabular}{|c|c|c|c|c|}
\hline Genotype MTBDRplus Ver 2.0 & $\begin{array}{l}\text { Smear-positive } \\
\text { Culture-positive } \\
(\mathrm{n}=1,166,87.0 \%)\end{array}$ & $\begin{array}{l}\text { Smear-positive } \\
\text { Culture-negative } \\
(n=22,1.6 \%)\end{array}$ & $\begin{array}{c}\text { Smear-negative } \\
\text { Culture-positive } \\
(n=152,11.3 \%)\end{array}$ & $\begin{array}{c}\text { Total } \\
(n=1,340)\end{array}$ \\
\hline Valid results with TUB band & $1,136(97.4)$ & $20(90.9)$ & $150(98.7)$ & $1,306(97.5)$ \\
\hline Valid results without TUB band & $2(0.2)$ & $0(0)$ & $1(0.6)$ & $3(0.2)$ \\
\hline Invalid results with TUB band & $5(0.4)$ & $2(9.1)$ & $0(0)$ & $7(0.5)$ \\
\hline Non-interpretable & $23(1.9)$ & $0(0)$ & $1(0.6)$ & $24(1.8)$ \\
\hline
\end{tabular}

Values are presented as number (\%).

Culture contamination ( $\mathrm{n}=46 / 1,614,2.8 \%$ [smear-positive, 24; smear-negative, 22]) and Smear-negative with culture-negative specimens $(\mathrm{n}=228 / 1,614,14.1 \%)$ were excluded from study. All smear-positive specimens were directly processed for LPA while, smear-negative specimens were processed for LPA only after culture came positive.

TUB: Mycobacterium tuberculosis; LPA: line probe assay.

Table 2. Mutation patterns among Mycobacterium tuberculosis isolates in Genotype MTBDRplus Ver 2.0 (n=1,340*)

\begin{tabular}{|c|c|c|c|c|}
\hline \multirow{3}{*}{$\begin{array}{c}\text { Resistant } \\
\text { patterns } \\
\text { (RIF/INH) }\end{array}$} & \multirow{3}{*}{$\begin{array}{c}\text { No. of strains } \\
(\%)\end{array}$} & \multicolumn{3}{|c|}{ Prominent mutation sites in resistant strain } \\
\hline & & \multirow{2}{*}{ RIF $(r p o B)$} & \multicolumn{2}{|c|}{ INH } \\
\hline & & & katG & $\operatorname{inh} A$ \\
\hline $\mathrm{S} / \mathrm{S}$ & $1,024(76.4)$ & - & - & - \\
\hline $\mathrm{S} / \mathrm{R}$ & $58(4.3)$ & - & $\begin{array}{l}\text { Codon 315: } 6 \text { (10.3) } \\
\text { S315T: } 44(75.9)\end{array}$ & $\begin{array}{l}\text { C15T: } 6(10.3) \\
\text { T8C: } 2(3.5)\end{array}$ \\
\hline $\mathrm{R} / \mathrm{S}$ & $12(1)$ & $\begin{array}{l}\text { Codon 510-517: } 1 \text { (8.3) } \\
\text { Codon 513-519: } 1 \text { (8.3) } \\
\text { Codon 526-529: } 1 \text { (8.3) } \\
\text { D516V: } 2 \text { (16.8) } \\
\text { S531 L: } 7 \text { (58.3) }\end{array}$ & - & - \\
\hline $\mathrm{R} / \mathrm{R}$ & $212(15.2)$ & $\begin{array}{l}\text { Codon 505-509: } 10(4.7) \\
\text { Codon 510-513: } 6(2.8) \\
\text { Codon 510-517: } 9(4.2) \\
\text { Codon 513-519: } 6(2.8) \\
\text { Codon 526-529: } 6(2.8) \\
\text { D516V: } 18(8.5) \\
\text { S531L: } 157(74.2)\end{array}$ & $\begin{array}{l}\text { Codon 315: } 11 \text { (5.2) } \\
\text { S315T: } 180(84.9)\end{array}$ & $\begin{array}{l}-15 /-16: 5(2.3) \\
\text { C15T: } 12(5.7) \\
\text { T8C: } 4(1.9)\end{array}$ \\
\hline $\mathrm{NI} / \mathrm{S}$ & $24(1.8)$ & Codon 530-533: 24 (100) & - & - \\
\hline
\end{tabular}

Values are presented as number $(\%)$.

*3 (0.2\%): valid results without TUB band; 7 (0.5\%): invalid results with TUB band.

RIF: rifampicin; INH: isoniazid; S: sensitive; R: resistant; NI: non-interpretable results (completely missing or light band of WT3 (codon 513 to 517) or WT8 (codon 530 to 533) without any MUT band); WT: wild-type; MUT: mutation; TUB: Mycobacterium tuberculosis.

valid results with TUB band, 1,024 of 1,340 specimens ( $76.4 \%)$ were observed to be sensitive to both RIF and INH drugs, 58 of 1,340 specimens $(4.4 \%)$ were INH mono-resistant, 12 of 1,340 (1\%) were RIF mono-resistant, multidrug resistant (MDR)-TB were found in 212 of 1,340 (15.8\%) (Table 2).

The most frequent mutation in RIF-resistant isolates was S531L substitution ( $\mathrm{n}=7,58.3 \%$ in RIF mono-resistant strain and $\mathrm{n}=157,74.2 \%$ in MDR-TB strain) in $r p o B$ gene, followed by at position D516V ( $\mathrm{n}=2,16.8 \%$ in RIF mono-resistant strain and $\mathrm{n}=18,8.5 \%$ in MDR-TB strain). Among INH resistant strain, $k a t G$ gene was found to be the most prominent mu- tated gene at site S315T $(\mathrm{n}=44,75.9 \%$ strains belong to INH mono-resistant and $n=180,84.9 \%$ were observed from MDRTB strains), whereas in inhA gene, C15T mutation site was the most common in both INH mono-resistant $(\mathrm{n}=6,10.3 \%)$ and MDR-TB strains ( $\mathrm{n}=12,5.7 \%)$. NI strains were observed in 24 specimens (1.8\%) and were further evaluated with pDST and DNA sequencing. 
Table 3. Comparison of phenotypic DST and sequencing with Genotype MTBDRplus Ver 2.0 in 24 non-interpretable Mycobacterium tuberculosis isolates

\begin{tabular}{|cccc|}
\hline & $\begin{array}{c}\text { Phenotypic results } \\
\text { (rifampicin) }\end{array}$ & $\begin{array}{c}\text { Change in amino acids } \\
\text { for } \mathbf{r p o B} \text { gene, } \mathbf{n} \text { (\%) }\end{array}$ & $\begin{array}{c}\text { No. of strains } \\
\text { (\%) }\end{array}$ \\
\hline $\begin{array}{c}\text { Strains (missing or light WT8 band in } r p o B \\
\text { gene with no mutation band) (n=24) }\end{array}$ & Resistant & L530P:2(9.1) & $22(91.7)$ \\
& & S531F: 6(27.2) & S531W: $10(45.5)$ \\
& & A532V:2(9.1) & L533P:2(9.1) \\
\hline
\end{tabular}

DST: drug susceptibility testing; WT: wild-type.

\section{Comparison of mutation patterns in NI with LPA, pDST, and sequencing}

For the evaluation of mutation patterns, all 24 NI strains (1.8\%) were put on pDST with standard critical concentration on both RIF and INH drugs. Among all NI, 22 (91.7\%) were resistant and two $(8.3 \%)$ were sensitive to RIF in pDST. Genetic analysis of $r p o B$ gene revealed five unique mutations that were not mentioned by the manufacturer in the operating manual for the Genotype MTBDRplus assay. Among all unique mutations, S531W substitution was found in 10 strains (45.5\%) followed by S531F substitution in six strains (27.2\%), L530P, A532V, and L533P substitutions equally distributed in two strains each (Table 3 ).

\section{Discussion}

In last decade, the use of several molecular diagnostic techniques like Xpert MTB/RIF and LPA have increased the DR-TB case notification rate worldwide ${ }^{12}$. RIF-resistant (RR) associated $r p o B$ gene hotspot (codon 507-533) is identified as the principle RR-TB defining region in all the nucleic acid amplification tests based molecular diagnostics ${ }^{13}$.

We found that a low proportion of LPA V.2 results are NI $(\mathrm{n}=24,1.8 \%)$. Silent mutations (WT3 [codon 514] and WT8 [codon 533]) and rare $r p o B$ gene mutations ${ }^{7,12}$ have been previously identified to cause NI results. In the recent version of LPA, mutation in WT8 band (codon 530-533) is a common cause of the NI result. In present study, $r p o B$ associated WT8 band was completely missing without presence of any MUT bands in the strips (defined as NI) thereby leading to diagnostic dilemma. As per the programmatic guidelines in India, all RIF mono-resistant patients are eligible for treatment as MDR patient ${ }^{1}$. This limitation associated with LPA V.2 may lead to patients either misdiagnosed as RIF-sensitive TB resulting in high failure and relapse rate or RR-TB resulting in unnecessarily being treated as MDR-TB ${ }^{14,15}$.

In this study, the most frequent mutation in $r p o B$ coded gene was found at codon S531L in both RIF mono-resistant $(\mathrm{n}=7,58.3 \%)$ as well as in MDR-TB isolates $(\mathrm{n}=157,74.2 \%)$ which is consistent with the previously published studies ${ }^{6,16,17}$. For the detection of INH resistant, LPA is equipped with two genes kat $G$ and $i n h A$, both of them showed similar frequency of mutation as published previously ${ }^{6}$. Apart from the predesigned mutation bands in $r p o B$ coded gene, other mutations like L530P ( $n=2,9.1 \%)$, S531F ( $n=6,27.2 \%)$, S531W ( $n=10$, $45.5 \%)$, A532V ( $n=2,9.1 \%)$, and L533P ( $n=2,9.1 \%)$ were observed in sequencing and these were also found resistant to RIF in pDST. In previous studies, disputed mutation at position L533P has been reported on both Lowenstein-Jensen and MGIT-960 culture medium ${ }^{18,19}$. Two specimens were sensitive to both sequencing and pDST. No MUT band was observed in LPA of these samples possibly due to failure of hybridization probe. The similar explanation has been quoted by Seifert et al. $(2016)^{10}$. These patients' isolates could have missed the proper resistant patterns to start the required treatment with single diagnostic test alone. This type of mutation frequencies was reported in $\geq 10 \%$ of total mutations associated with $r p o B$ gene $^{19}$. Mutation at codon 533 (L533P) is likely to be missed by Xpert MTB $/ \mathrm{RIF}^{20}$, but usually detected in LPA V.2, as seen in present study also (L533P $[\mathrm{n}=2,9.1 \%])$. LPA V.2 covers more coverage regions of $r p o B$ gene (from codon 505 to 534) when compared to Xpert MTB/RIF (codon 509 to 533$)^{20}$. However, some other deletions were also noted within and out of the hot spot region of $r p o B$ gene which were associated with low level resistant in $\mathrm{pDST}^{21,22}$. Sequencing aided the identification of some other polymorphism in $r p o B$ gene also. This finding of our study underscores that uncommon and/or silent mutation can cause NI results which can cause therapeutic dilemmas. Similarly, Nikam et al. ${ }^{23}$ observed NI results in both RIF and INH without mentioning any specific loci of genes in MTBDRplus assay. Their study also highlighted this limitation of LPA which is especially of concern in TB endemic areas.

Therefore, this study highlights the limitations of LPA in detection of mutation patterns associated WT8 region (codon $530-533)^{7}$. To overcome this limitation, pDST and sequencing are recommended in select cases, such as NI results from 
LPAs. In the present study, we showed the usefulness of pDST and sequencing for elucidating the NI results from the Genotype MTBDRplus assay.

In most real-life scenario in high TB burden areas, sequencing may not be feasible. pDST can be a reasonable alternative in resource-limited settings. However, more prospective studies with clinical correlation can throw more light in this regard.

In the present study, we found that a small proportion of clinical samples were reported as NI in the Genotype MTBDRplus assay. Almost all of the strains with NI results $(22 / 24,91.7 \%)$ were $\mathrm{RR}$ in the pDST. Sequencing detected various rpoB mutations in these 22 cases. These results suggest that pDST and $r p o B$ sequencing are useful in elucidating the cause and determining the clinical meaning of NI results from the Genotype MTBDRplus assay.

\section{Author's Contributions}

Conceptualization: Singh BK, Sharma R, Soneja M. Methodology: Singh BK, Sharma R, Soneja M, Jorwal P. Formal analysis: Singh BK, Sharma R. Software: Singh BK, Sharma R. Validation: Singh BK, Sharma R, Soneja M, Ramachandran R, Nischal N, Biswas A, Sarin S, Wig N. Investigation: Singh BK, Sharma R, Soneja M, Jorwal P, Nischal N. Writing - original draft preparation: Singh BK, Sharma R. Writing - review and editing: Soneja M, Kodan P, Nischal N, Biswas A, Sarin S, Wig N. Approval of final manuscript: all authors.

\section{Conflicts of Interest}

No potential conflict of interest relevant to this article was reported.

\section{Acknowledgments}

We are very thankful to Central TB Division, Ministry of Health \& Family Welfare, Govt. of India; State TB Cell, National Capital Territory (NCT) of Delhi, Delhi; Foundation For Innovative New Diagnostics (FIND) India for logistic and technical support. Authors acknowledge support of lab personnel of Department of Medicine in carrying out this study.

\section{Funding}

No funding to declare.

\section{References}

1. World Health Organization. Global tuberculosis report 2019 [Internet]. Geneva: World Health Organization; 2019 [cited 2020 Mar 2]. Available from: http://www.who.int/tb/publications/global_report/en/.

2. Nathavitharana RR, Cudahy PG, Schumacher SG, Steingart KR, Pai M, Denkinger CM. Accuracy of line probe assays for the diagnosis of pulmonary and multidrug-resistant tuberculosis: a systematic review and meta-analysis. Eur Respir J 2017;49:1601075.

3. World Health Organization. WHO policy statement: molecular line-probe assays for rapid screening of patients at risk of multidrug-resistant tuberculosis. Geneva: World Health Organization; 2008.

4. World Health Organization. The use of molecular line-probe assay for the detection of resistance to isoniazid and rifampicin: policy update. WHO/HTM/TB/2016.12 [Internet]. Geneva: World Health Organization; 2016 [cited 2020 Mar 2]. Available from: http://apps.who.int/iris/bitstream/handle/10665/ 250586/9789241511261-eng.pdf?sequence=1\&isAllowed=y.

5. World Health Organization. Rapid implementation of the Xpert MTB/RIF diagnostic test: technical and operational 'how to' practical considerations [Internet]. Geneva: World Health Organization; 2011 [cited 2012 Jan 13]. Available from: http://whqlibdoc.who.int/publications/2011/ 9789241501569_eng.pdf.

6. Barnard M, Gey van Pittius NC, van Helden PD, Bosman M, Coetzee G, Warren RM. The diagnostic performance of the GenoType MTBDRplus version 2 line probe assay is equivalent to that of the Xpert MTB/RIF assay. J Clin Microbiol 2012;50:3712-6.

7. GenoType MTBDRplus, ver 2.0. Instructions for use [Internet]. Nehren: Hain LifeScience GmbH; 2013 [cited 2018 Nov 30]. Available from: https://www.ghdonline.org/uploads/ MTBDRplusV2_0212_304A-02-02.pdf.

8. Van Deun A, Aung KJ, Hossain A, de Rijk P, Gumusboga M, Rigouts L, et al. Disputed rpoB mutations can frequently cause important rifampicin resistance among new tuberculosis patients. Int J Tuberc Lung Dis 2015;19:185-90.

9. Jo KW, Lee S, Kang MR, Sung H, Kim MN, Shim TS. Frequency and type of disputed rpoB mutations in Mycobacterium tuberculosis isolates from South Korea. Tuberc Respir Dis 2017;80:270-6.

10. Seifert M, Georghiou SB, Catanzaro D, Rodrigues C, Crudu V, Victor TC, et al. MTBDRplus and MTBDRsl assays: absence of wild-type probe hybridization and implications for detection of drug-resistant tuberculosis. J Clin Microbiol 2016;54:912-8.

11. Williams DL, Waguespack C, Eisenach K, Crawford JT, Portaels F, Salfinger M, et al. Characterization of rifampinresistance in pathogenic mycobacteria. Antimicrob Agents Chemother 1994;38:2380-6.

12. World Health Organization. Global tuberculosis report 2013. 
Geneva: World Health Organization; 2013.

13. Sharma SK, Chaubey J, Singh BK, Sharma R, Mittal A, Sharma A. Drug resistance patterns among extra-pulmonary tuberculosis cases in a tertiary care centre in North India. Int J Tuberc Lung Dis 2017;21:1112-7.

14. Hofmann-Thiel S, Hoffmann H, Hillemann D, Rigouts L, Van Deun A, Kranzer K. How should discordance between molecular and growth-based assays for rifampicin resistance be investigated? Int J Tuberc Lung Dis 2017;21:721-6.

15. Paramasivan CN, Raizada N. Line probe assay: a look at noninterpretable results. Int J Tuberc Lung Dis 2016;20:146.

16. Yadav RN, Singh BK, Sharma SK, Sharma R, Soneja M, Sreenivas V, et al. Comparative evaluation of GenoType MTBDRplus line probe assay with solid culture method in early diagnosis of multidrug resistant tuberculosis (MDR-TB) at a tertiary care centre in India. PLoS One 2013;8:e72036.

17. Singh BK, Sharma SK, Sharma R, Sreenivas V, Myneedu VP, Kohli M, et al. Diagnostic utility of a line probe assay for multidrug resistant-TB in smear-negative pulmonary tuberculosis. PLoS One 2017;12:e0182988.

18. Andres S, Hillemann D, Rusch-Gerdes S, Richter E. Occurrence of rpoB mutations in isoniazid-resistant but rifampin- susceptible Mycobacterium tuberculosis isolates from Germany. Antimicrob Agents Chemother 2014;58:590-2.

19. Van Deun A, Aung KJ, Bola V, Lebeke R, Hossain MA, de Rijk $\mathrm{WB}$, et al. Rifampin drug resistance tests for tuberculosis: challenging the gold standard. J Clin Microbiol 2013;51:263340.

20. Rufai SB, Kumar P, Singh A, Prajapati S, Balooni V, Singh S. Comparison of Xpert MTB/RIF with line probe assay for detection of rifampin-monoresistant Mycobacterium tuberculosis. J Clin Microbiol 2014;52:1846-52.

21. Van Deun A, Barrera L, Bastian I, Fattorini L, Hoffmann H, Kam KM, et al. Mycobacterium tuberculosis strains with highly discordant rifampin susceptibility test results. J Clin Microbiol 2009;47:3501-6.

22. Mani C, Selvakumar N, Narayanan S, Narayanan PR. Mutations in the rpoB gene of multidrug-resistant Mycobacterium tuberculosis clinical isolates from India. J Clin Microbiol 2001;39:2987-90.

23. Nikam C, Patel R, Sadani M, Ajbani K, Kazi M, Soman R, et al. Redefining MTBDRplus test results: what do indeterminate results actually mean? Int J Tuberc Lung Dis 2016;20:154-9. 